\title{
PHYSICAL OBJECTS ON NAVIGATION CHANNAL SIMULATION MODELS
}

\author{
Daniel de Oliveira Mota \\ Newton Narciso Pereira \\ Rui Carlos Botter \\ Afonso Celso Medina \\ Department of Naval Architecture and Oceanic Engineering \\ Polytechnic School University of Sao Paulo \\ Av. Professor Mello Moraes, 2231 Sao Paulo, SP 05508-030, BRAZIL
}

\begin{abstract}
This paper presents the results of a simulation using physical objects. This concept integrates the physical dimensions of an entity such as length, width, and weight, with the usual process flow paradigm, recurrent in the discrete event simulation models. Based on a naval logistics system, we applied this technique in an access channel of the largest port of Latin America. This system is composed by vessel movement constrained by the access channel dimensions. Vessel length and width dictates whether it is safe or not to have one or two ships simultaneously. The success delivered by the methodology proposed was an accurate validation of the model, approximately $0.45 \%$ of deviation, when compared to real data. Additionally, the model supported the design of new terminals operations for Santos, delivering KPIs such as: canal utilization, queue time, berth utilization, and throughput capability.
\end{abstract}

\section{INTRODUCTION}

Discrete event simulation models have been developed over decades, originally designed to capture the randomness of a system, by the abstraction of system components, such as a box, a gear, a package, or even a person. This abstraction, named entity, runs over the system seizing resources like machines, conveyor belts, or workers. A queue is generated based on whether the resource is available or not to be seized. This paradigm has been used and taught many times to measure capacity of a system, queue levels and leadtimes.

The purpose of this paper is to extend the concept of entity used in simulation to the concept of model physical objects (or physical entities). In this concept, physical characteristics, such as the width, length, weight and any other attribute necessary to provide more realistic constrains in the system representation. So, the motivation for this study was the necessity to consider crossing vessels constraints in a navigation access channel of a maritime system. We applied the technique shown in this paper in the biggest port of Latin America, where small ships can freely cross in different directions, but large (and wide) ones should wait until the channel is free because it is not safety to have it moving toward another vessel. The results achieved by the model used in this study delivered a $0.45 \%$ of deviation at the validation parameters when compared with real life indicators.

This paper is organized as follows:(1) a brief introduction to the modeling technique proposed by this paper; (2) a literature review of the modeling technique, comparing and contrasting previous work using physical objects simulation; (3) details of the modeling technique proposed; (4) a case study example where this technique was successfully applied; (5) conclusions of the study; and finally (6) discussion about extensions of this study. 


\section{LITERATURE REVIEW}

\subsection{Traditional use of discrete event simulation}

Traditionally, the discrete event simulation has been used under industrial systems (Guimaraes and Diallo 2012, Katchasuwanmanee and Cheng 2012), where it was used to be strong at, but also a more modern approach encourages its use in supply chain systems (Katchasuwanmanee and Cheng 2012), maintenance, and recently in health care (Wongsammacheep, Pichitlamken, and Weerawat 2012), humanitarian logistics (Heaslip 2013), and service sector (Yang, Allen, Fry, and Kelton 2012). Particularly under the maritime logistics subjects, it can be distinguished some similar work, in which it was not used the physical objects approach (Almaz and Altiok 2012). This author used Arena simulation software (Kelton, Sadowski, and Sadowski 2002), manufactured by RockwellAutomation ${ }^{\circledR}$, to measure the impact of deeping on port performance. On his work, the author modeled the vessel traffic in Delaware River using a comprehensive level of details (vessels types, demand expected increase, and a statistical analysis about the data used), however it was not mentioned how the crossing between two vessels was tackled. From a practical stand point, this is an important source of ships delay, remaining in the moor area, waiting until the canal is free to be accessed.

\subsection{Attempts to model physical objects}

Turk (Sweeney, Norton, Bacon, Haumann, and Turk 1991) was the first researcher to report a paper in wintersimulation conference the use physical aspects of an object in the simulation model. However, on her work, the focus was given to the animation process, with the purpose of having a more realistic view of the object. In the same paper the author describes the structure of the object focusing on the points, edges, faces, and cells. Then, all elements described previously was combined under a hierarchical logic creating the motion animation expected. This approach is complex, however the purpose is different from the one reported in this paper. In an animation system, there is no intention in conducting statistical analysis over resources. Another author (Hoffmann and Hopcroft 1987) stepped through the same path using the simulation of physical systems motivated by body movement. The intention was to employ into the Automation and Robotics research field. This study found basement in a dynamic model using differential equations to abstract objects classified as primitive and composites, where the first is a basic structure to build the second one.

Up to the date of this paper development, no other attempt was found to integrate the powerfulness of discrete event simulation capability in handling statistical analysis into system, with probability distribution randomness, queue scheme, and seize-delay-release paradigm to dimension a production system considering spatial constraints that limits movement of the physical objects entities.

\subsection{Physical constraints of a channel system}

According to PIANC (International Association of Lighthouse Authorities and International Maritime Pilots Association 1995), a channel width should be a multiple of the ships beam, and the most important variable to take whether it is permitted or not, to have two ships crossing moving toward opposite directions simultaneously. This constraint is calculated using the diagram below (Figure1). More details regarding to the crossing constraints mentioned in this document can be found at PIANC documentation.

In the figure below (Figure1) it can be identified the beam of each ship $B_{1}, B_{2}$ is added to some security parameters related to each ship $W m_{1}, W m_{2}$ as well as parameters related to the space between the shores $W_{b r}, W_{p}, W_{b g}$. 


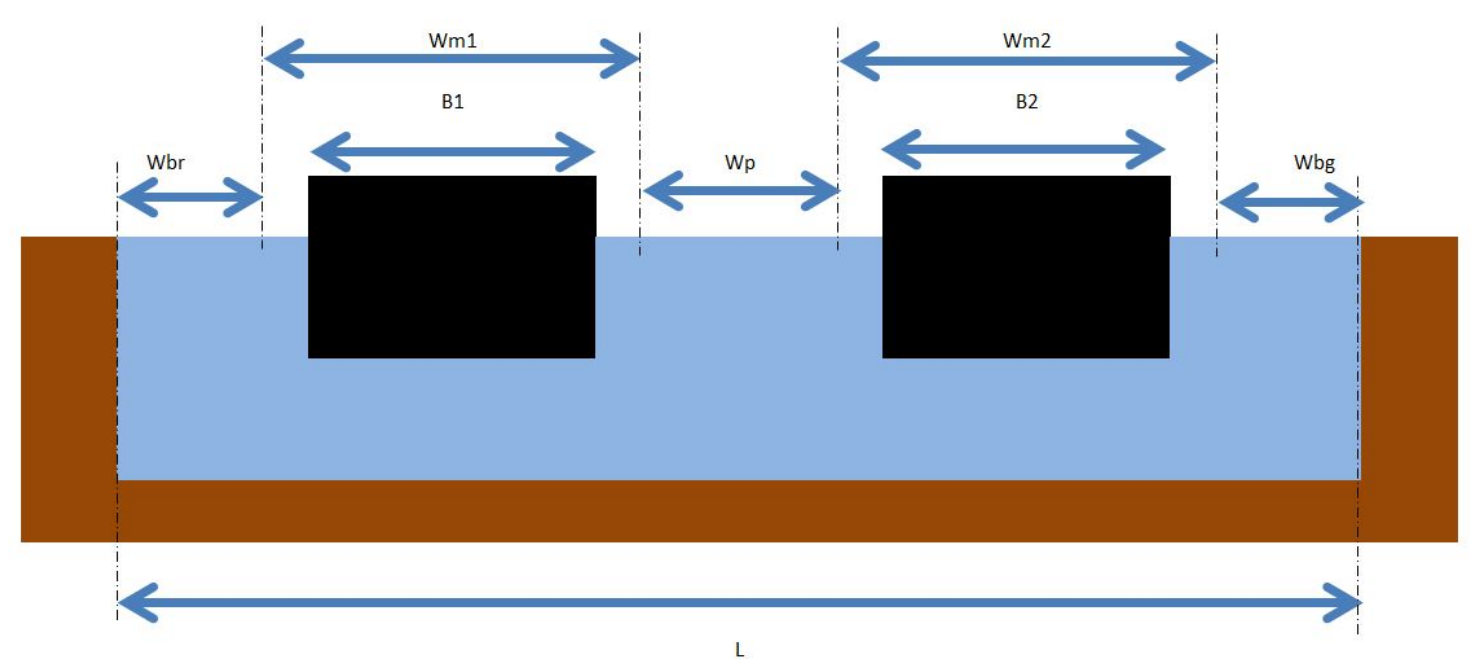

Figure 1: Width of a channel parameters to be considered vessels crossing.

\section{METHODOLOGY}

\subsection{Model description}

If it is considered a free space such as a wide road, or a plan lane with dimensions $L$ and $W$, where the first corresponds for the total length of the space and the second representing the total width of the space. This space is partitioned into proportional pieces represented by $l$ the length of the subdivision, and $w$ the width of the subdivision, as well. Further, it was considered an object with dimensions $O L$, and $O W$ to represent the object length and width. Assuming that the orientation of length and width is just a matter of reference. The length is oriented to the same direction of the object movement, hence, the velocity vector. The system modeled can be divided into three subsystems: (1) space; (2) objects; and (3) environment.

\subsubsection{Defining space}

Space represents an abstraction of the floor, or the terrain in which the entity will be placed. At this point it should be plane, and free of obstacles. Mathematically a space is defined as the following (Figure 2):

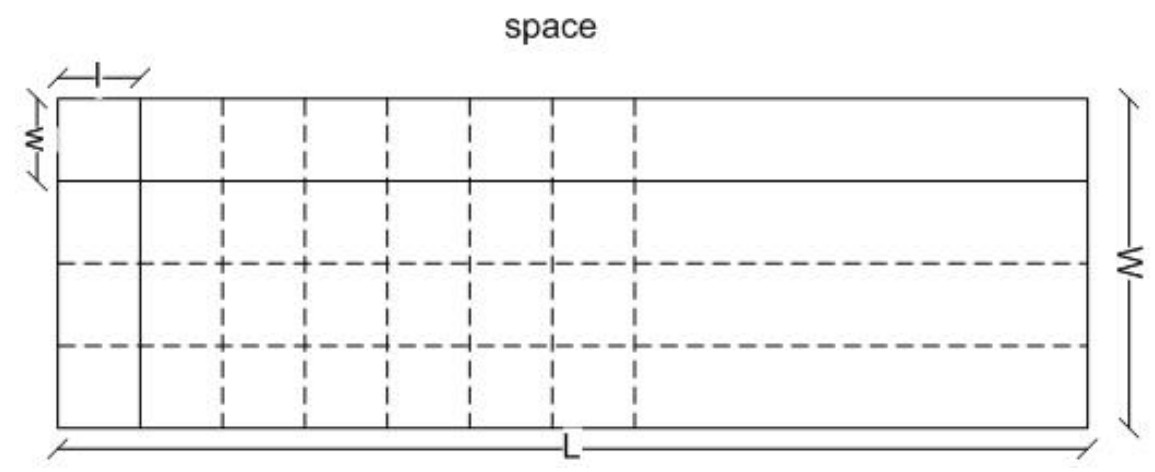

Figure 2: Abstract representation of the space.

$\mathrm{L}=$ length of the space

$\mathrm{W}=$ width of the space 
1 as the size of the smallest portion of the space length

$\mathrm{W}$ as the size of the smallest portion of the space width

$\mathrm{S}_{l}=$ maximum number of portions in length direction

$\mathrm{S}_{w}=$ maximum number of portions in width direction

$$
\begin{gathered}
\mathrm{S}_{l} * l=L \\
\mathrm{~S}_{w} * w=W
\end{gathered}
$$

\subsubsection{Defining object}

The object represents the abstraction element of a vessel, forklift, or any entity that moves over the space. It is placed in the space, according to the mathematical definition below:

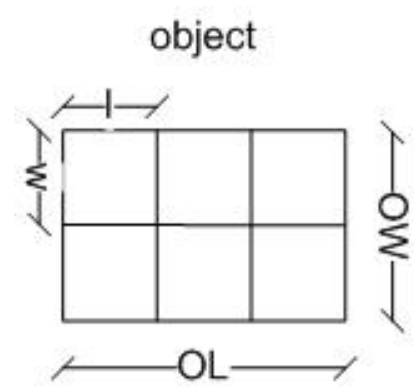

Figure 3: Abstract representation of the object.

$\mathrm{OL}=$ length of the object

$\mathrm{OW}=$ width of the object

$\mathrm{k}_{i}$ multiplier to scale the object toward length direction

$\mathrm{k}_{j}$ multiplier to scale the object toward width direction

$\mathrm{OS}_{l}=$ maximum number of portions of the object in length direction

$\mathrm{OS}_{w}=$ maximum number of portions of the object in width direction

$$
\begin{gathered}
\mathrm{k}_{i} * O S_{l}=O L \\
\mathrm{k}_{j} * O S_{w}=O W
\end{gathered}
$$

Since the scope of this research is just investigating a single direction movement of the object, it is just subjected to movement toward the length direction, hence, mathematically we have:

$$
\begin{gathered}
\frac{\partial \vec{l}}{\partial t}=\vec{v}_{l} \\
\frac{\partial \vec{w}}{\partial t}=\overrightarrow{v_{w}}=0
\end{gathered}
$$




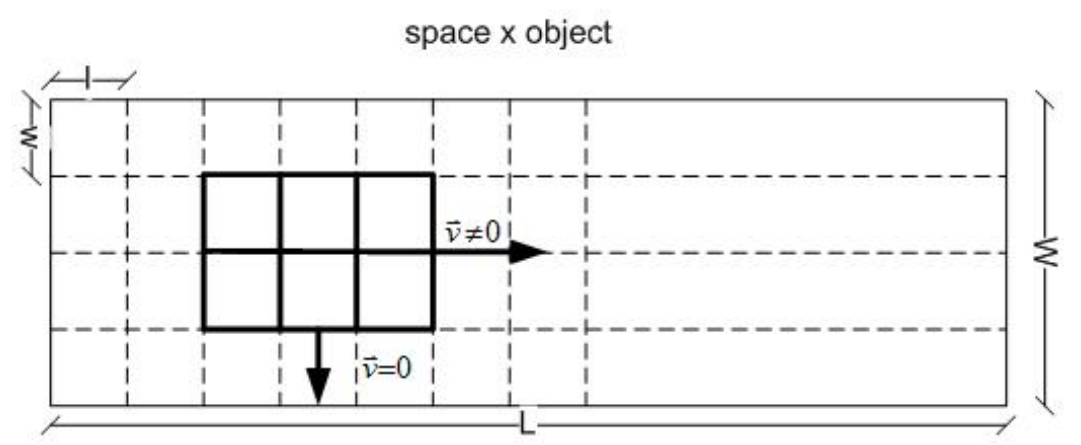

Figure 4: An object incorporated into the space.

\subsubsection{Defining environment}

The environment is an abstraction of how one object interacts with another. The interaction among the objects in a channel system is observed when there is a minimum distance between each object in which the one coming behind is not allowed to move if there is not a free space to move to the front. This situation is common when considered a physical object. In a channel, a vessel cannot move if it is too close of the one in front of it. We can define this distance as security gap $(d)$.

\section{Environment security area of an object}

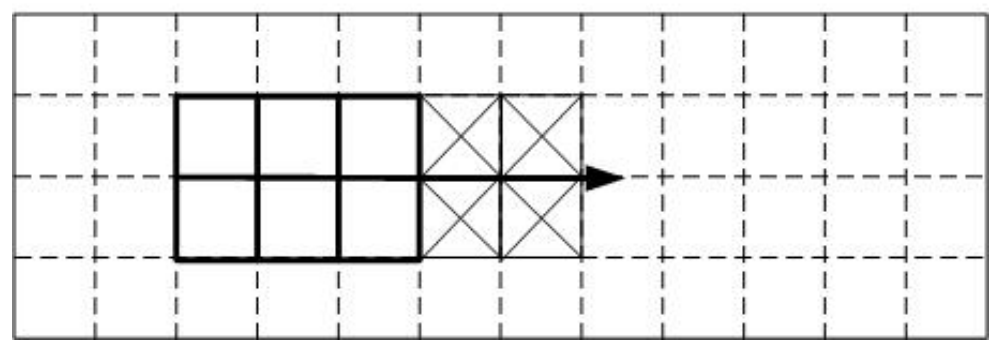

Figure 5: An object incorporated into the space, considering the security gap.

Since, this distance should be defined as an integer number of portions of length $l$, mathematically, it can be defined as:

$$
d=k_{d} * l
$$

\subsubsection{Entrance and departure process}

When all those elements are put together to interact, there are two important moments of the objects journey that requests special attention: (1) entrance; (2) departure. The object entrance requires to be observed the security gap in order to not conflict and, in real life, have a crash. On the other hand, the ending part of the object should be identified so that this object will not block the entrance of another object. The same attention should be paid to avoid blocking the space with an object that is not there anymore. Under the modeling perspective, during both the entrance and the departure, the objects are subjected to the variation of its length over time, because it is releasing a boundary region, and is not seizing the next free space. This movement can be observed in the figure below (Figure 6). 


\section{Mota, Pereira, Botter, and Medina}

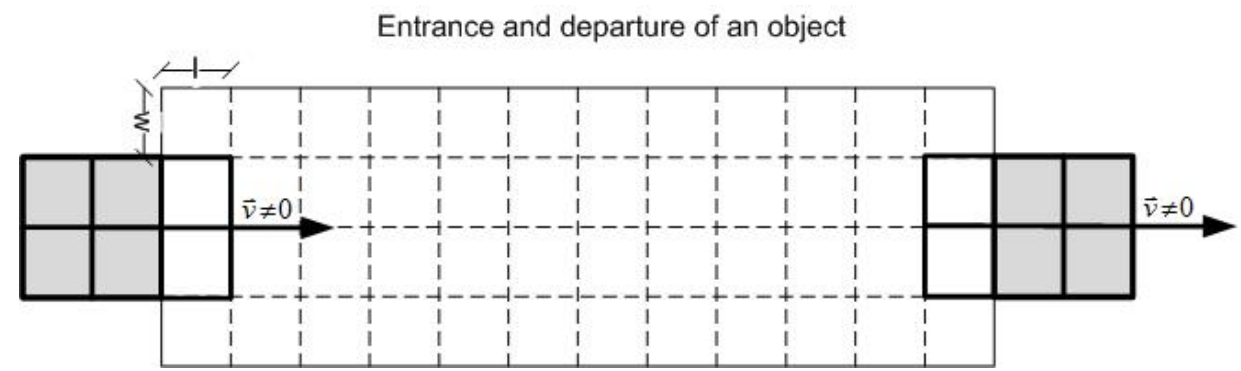

Figure 6: An object incorporated into the space.

\section{EXPERIMENTS}

For the purpose of using this study in a real life problem, the methodology proposed by this paper was the application into a maritime transportation canal explained in the following section.

\subsection{Case study}

Port of Santos handles around 97.12 million tons per year, this number represents the production of 2011, but this demand is increasing yearly given the importation and exportation level Brazil has faced. It classifies Santos as the largest port in Latin America. Composed by 59 mooring berths along the access waterway to the port, located on both left and right shore. Santos counts on an area of 7.7 million $\mathrm{m}^{2}, 3.7$ million $\mathrm{m}^{2}$,on the Right Shore, and 4.0 million $\mathrm{m}^{2}$ on the Left Shore. It has 13 kilometers of extension length, 55 kilometers of ducts, 100 kilometers of railway road. The tidal variation is of 1.2 meters. It has a storage area of 700 thousand $\mathrm{m} \mathrm{m}^{3}$, and a storage capacity of above 2.5 million tons. Even though it is classified as public, some terminals of the ports might be whether public of private, depending on the contracts agreed with the government. It operates several cargo types, being container the most important type of ships berths on its terminals. In the figure below, the channel could be observed (Figure 7).

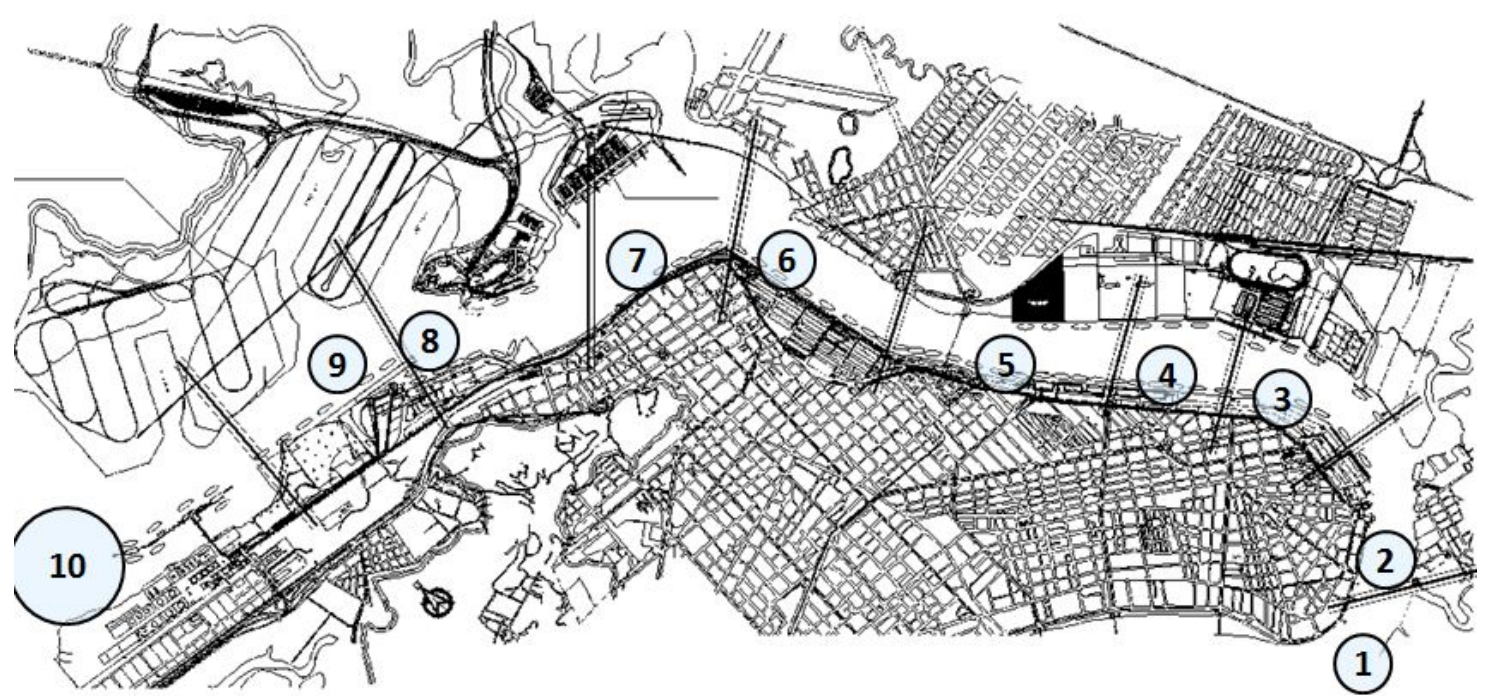

Figure 7: Santos Channel representation, with the partitions identified. 
Conceptually the ships follow the steps: access waterway of port considering its arrival, navigation through the channel, mooring, loading of ship, and unmooring. The modeling of this ships operation at Port of Santos was based on the ship timeline proposed by the author (Figure 8).

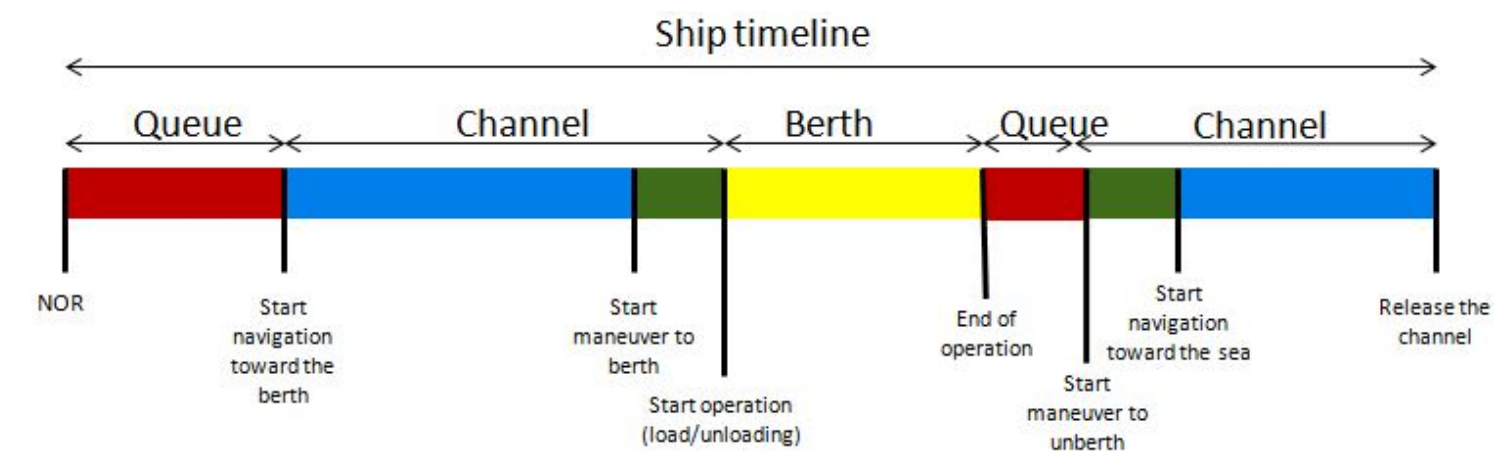

Figure 8: Timeline of a regular ship .

\subsection{Model parameters}

As this model was developed using a Discrete Event Simulation tool - Arena (Kelton, Sadowski, and Sadowski 2002), regular parameters should be set in table below (Table 1).

Table 1: Table parameters.

\begin{tabular}{clcc}
\hline Index & Parameter & Value & Units \\
\hline 1 & Number of replucations & 10 & - \\
2 & Replication duration & 365 & days \\
3 & W & 220 & meters \\
4 & L & 13000 & meters \\
5 & w & TRIA $(20,30,50)$ & meters \\
6 & 1 & TRIA $(100,200,300)$ & meters \\
7 & $S_{l}$ & 130 & units \\
8 & $S_{w}$ & 10 & units \\
9 & d & 2000 & meters \\
\hline
\end{tabular}

\subsubsection{Waterway: Space}

Space in where all characteristics from physical part of channel. It is defined as a subdivision of the channel, with configurable length and width in which several properties can be parameterized and will generate impact on ships moves inside the channel. In this subsystem there are the following configurations: (1) Channel width: indicates distance between channel shores. This distance will be analyzed at the entering of each ship, in case PIANC rule is active; (2) Channel speed: (in knots) velocity of the ship while crossing the channel. This speed is separately associated to the regular fleet of channel and to specific fleet ships. Finally (3) Time of maneuver: this parameter, in minutes, define the time spent by ship when, at mooring, it needs to stay at the channel realizing any type of maneuver (rotation) (Gray, Waters, Blume, and Landsburg 2003). 


\subsubsection{Berths: Resources}

Berths consolidates all characterization of process stage where the ships should reach to proceed the loading/unloading to meet a demand at the system. The fundamental parameter in this subsystem is demand (in tons/year) of the berth. This demand will generate a number of watercrafts great enough to load and unload all those cargo using ships. To meet the demand, berths represents mooring points that will accommodate ships. The number of accommodated ships at the same time is equal to number of berths.

\subsubsection{Ships: Objects}

Ships are abstracted by the concept of objects described previously associates to the entities of system its basic configurations: (1) Draught; (2) Length; (3) Cargo; (4) Width (mouth). In each traffic moment, some of these characteristics will be requested to make a decision about the model. For instance, length generates higher or shorter enter restriction to a new vessel at the waterway. Width restricts two-way traffic or simples, if the waterway is operating under PIANC rule. Draught could be used to evaluate waterway availability regarding tide, permitting or not the entry of vessels.

\subsubsection{Security gap: Environment}

To have security over the operations, Port of Santos authority states the mandatory distance of 2,000 meters between vessels in order to avoid collisions and crashes in the channel. This distance depends on the condition of the channel under the water, considering the presence of rocks, mud, or a sunk vessel that was not withdrawn after the accident. Unfortunately Santos is known by the restrictions of draught mainly due to rocks and the sunk vessel named Ais Giorgis.

\section{MODEL VERIFICATION AND VALIDATION}

To proceed with simulation, it was necessary to verify the validity of a developed model (Chwif and Medina 2006). At validation process, we evaluated if the model was operating according to the real system. So, the first models test was using data from a known period and it was compared the output generated by the model with registered value of movement at port. If those values are close enough to the reality (Sargent 2012), model can be considered as validated. The construction of validation scenario was based on data given by CODESP, according to the list below (Year 2011): (1) 59 berths 49 publics and 10 privates; (2) Demands CODESP (Companhia Docas do Estado de Sao Paulo) data; (3) Channel cross: respecting PIANC rule; (4) Breadth of channel: $2 \mathrm{~km}$ per partition; (5) 25 of fleet makes, in front of destiny terminal, maneuver spin, taking a average of 30 minutes; (6) Channel width: 220 meters. Results of validation scenario are presented in Table 2.

Table 2: Validation results.

\begin{tabular}{clcccc}
\hline Index & KPI & Data & Model & Units & Deviation \\
\hline 1 & Number of vessels & 6,327 & 6,294 & ships per year & $0.5 \%$ \\
2 & Average draught & 11.4 & 11.5 & meters & $0.9 \%$ \\
3 & Average length & 212.4 & 213.1 & meters & $0.3 \%$ \\
4 & Average width & 30.7 & 30.6 & meters & $0.3 \%$ \\
5 & Average navigation time (including queue) & 42 & 41 & hours & $1.8 \%$ \\
6 & Average complete timeline & 70.7 & 70.6 & hours & $0.1 \%$ \\
7 & Total cargo loaded/unloaded & 95 & 95 & mtpy & $0.0 \%$ \\
8 & Average operations time & 37.5 & 37.4 & hours & $0.2 \%$ \\
9 & Average navigation time (without queue) & 1.36 & 1.36 & hours & $0.0 \%$ \\
\hline
\end{tabular}




\section{DISCUSSION}

The main contribution delivered by this modeling technique is the incorporation of physical objects concepts to include in the model the spatial constraints of the simulated system. By the interaction between the object and the environment, for instance in an access channel of a port, several operational limitation was considered. Moreover, costly infrastructure investments could be precisely evaluated before the construction project effectively starts.

This study represents a relevant progress in modelage paradigm toward more realistic models with low computational costs (the base case of the model with 10 replications runs in less than 2 minutes). Even though, there are several situations in which this type of constraints exists in a supply chain context. For example, the modelage of a warehouse system is a very recurrent theme seen in simulation models (Henderson, Biller, Hsieh, Shortle, Tew, and Barton 2012). And, the use of simulation to estimate the number of transporters is relatively commom (Mariano and Kuri-Morales 2012). However, a warehouse is extremely space constrained since the better the space is used of storing materials, the higher a warehouse is profitable (of course assuming a well managed one). So, the available space in a corridor to allocate two forklifts may be restrictive, what constrains the number of vehicles used to handle the objects. Thus, additional examples can be found in manufacturing, and supply chain, as well (Chan and Prakash 2012).

Other authors (Subramanya 2012) used discrete event simulation to analyze the capacity of a logistic system, even in maritime systems like this work. But under the author perspective, they oversimplified an important (and not straight forward) assumption of the problem: the physical aspects of the objects, oversimplifying the allocation problem, driving the decision maker to naive conclusions in terms of resource allocation.

\section{CONCLUSION}

Our conclusion is toward the confirmation that is extremely feasible to apply the technique described in this paper in complex systems like a navigation channel. The results delivered by the simulation shows a strong adherence to the real data if the spatial constraints are embedded to the operational constraints. In the study case studied, this modelage approach has shown an efficient way to mimic a bottlenecked system with an intense vessels moviment. Particularly in the system represented, we tested scenarios of the increase of ships movement at Santos channel. Hence, we identified that from 6,000 ships/year (doubling the number of vessels per year), waiting time at access channel did not increase significantly in comparison to the current time.

Moreover, new berths installation along the channel was tested as well. We analyzed operation policies of ships at access channel, space between the ships, speed and crossing scenarios. Finally, it is important to consider that to attend higher demands new operational policies should be tested at port. For instance, the reduction at spaces between ships, as well as a better programming of enter and exit.

Further, this technique will be applied in different contexts from the one reported in this paper, as well as comparison with different models will be made to compare which type of ofjects in a model should, or should not be modeled as a physical object.

\section{REFERENCES}

Almaz, O. A., and T. Altiok. 2012. "Simulation modeling of the vessel traffic in Delaware River: Impact of deepening on port performance". Simulation Modelling Practice and Theory 22:146-165.

Automation, Rockwell 2013. "Arena Simulation Software by Rockwell Automation".

Chan, F. T., and A. Prakash. 2012. "Inventory management in a lateral collaborative manufacturing supply chain: a simulation study". International Journal of Production Research 50 (16): 4670-4685.

Chwif, L., and A. C. Medina. 2006. Modelagem e simulação de eventos discretos. Afonso C. Medina. 
Gray, W. O., J. K. Waters, A. L. Blume, and A. C. Landsburg. 2003. "Channel design and vessel maneuverability: next steps". Marine Technology 40 (2): 93-105.

Guimaraes, A. M. C., and M. Diallo. 2012. "Using Simulation in an Industry of Gasket Products: A Case Study". Engineering Management Research 1 (2): p153.

Heaslip, G. 2013. "Services Operations Management and Humanitarian Logistics". Journal of Humanitarian Logistics and Supply Chain Management 3 (1): 3-3.

Henderson, S., B. Biller, M. Hsieh, J. Shortle, J. Tew, and R. Barton. 2012. "A simulation model to improve warehouse operations". In Proceedings, Winter Simulation Conference, Volume 2018.

Hoffmann, C., and J. Hopcroft. 1987. "Simulation of physical systems from geometric models". Robotics and Automation, IEEE Journal of 3 (3): 194-206.

International Association of Lighthouse Authorities and International Maritime Pilots Association 1995. Approach Channels: Preliminary Guidelines. Pianc.

Katchasuwanmanee, K., and K. Cheng. 2012. "Complexity in manufacturing supply chain applied to automotive industry: Modelling, analysis and a case study". In Proceedings of the 37th International Matador Conference, Volume 6, 255. Springer.

Kelton, W. D., R. P. Sadowski, and D. A. Sadowski. 2002. Simulation with ARENA, Volume 2. McGraw-Hill New York.

Mariano, C. H., and A. F. Kuri-Morales. 2012. "Complex componential approach for redundancy allocation problem solved by simulation-optimization framework". Journal of Intelligent Manufacturing:1-20.

Sargent, R. G. 2012. "Verification and validation of simulation models". Journal of Simulation 7 (1): 12-24.

Subramanya, K. 2012. "Machine Capacity Estimation in a Process Industry using Simulation Modeling-A Case Study". International Journal of Social Sciences and Humanities 1 (1): 8-12.

Sweeney, P., A. Norton, R. Bacon, D. Haumann, and G. Turk. 1991. "Modelling physical objects for simulation". In Proceedings of the 23rd conference on Winter simulation, 1187-1193. IEEE Computer Society.

Wongsammacheep, T., J. Pichitlamken, and W. Weerawat. 2012. "The discrete-event simulation model of a health screening center". Lecture Notes in Management Science 4:54-63.

Yang, M., T. T. Allen, M. J. Fry, and W. D. Kelton. 2012. "The Call for Equity: Simulation-Optimization Models to Minimize the Range of Waiting Times". IIE Transactions (just-accepted).

\section{ACKNOWLEDGEMENTS}

Special thanks to the National Council for the Improvement of Higher Education (CAPES), who provided financial support of developing this research (Grant Procs. DS).

\section{AUTHOR BIOGRAPHIES}

DANIEL DE OLIVEIRA MOTA is a researcher from CILIP (Innovation Center for Logistics and Ports Infrastructure) situated in School of Engineering at University of Sao Paulo. He graduated in 2009 with an M.S. in Management Science and Operations Research from North Carolina Agricultural and Technical State University, USA. He developed and managed over 20 projects as a consultant using Arena in humanitarian logistics, health care, supply chain, mining, and steel company. He also researches modeling techniques of stochastic systems: simulation, queueing theory, and Markov decision process. His email is danielmota@usp.br.

RUI CARLOS BOTTER is a Full Professor at the Polytechnic School (College of Engineering) at University of Sao Paulo, Brazil. He holds a $\mathrm{PhD}$ and Master Degree in Naval Architecture and Oceanic Engineering at the Polytechnic School (College of Engineering). He has more than 25 years that experience in logistics and ports development. His email is rcbotter@usp.br. 
NEWTON NARCISO PEREIRA is the Senior Researcher of Innovation Centre of Logistics and Ports Infrastructure at the Polytechnic School (College of Engineering) at University of Sao Paulo, Brazil. He holds a bachelor degree in Naval Technologist and Industrial Engineering, $\mathrm{PhD}$ and Master Degree in Naval Architecture and Oceanic Engineering at the Polytechnic School (College of Engineering) at University of Sao Paulo. He is been developing a Post-doctoral in Naval Architecture and Oceanic Engineering at the Polytechnic School. His email is newton.pereira@usp.br

AFONSO CELSO MEDINA is a Naval Engineer and holds Master Degree in Naval Architecture and Oceanic Engineering at the Polytechnic School (College of Engineering) at University of Sao Paulo. He is a Senior Researcher at Department of Naval Architecture and Oceanic Engineering at the Polytechnic School and works with discrete events simulation and optimization. His email is afmedina@gmail.com. 